\title{
A Typical Basalt Platform Landslide: Mechanism and Stability Prediction of Xiashan Landslide
}

\author{
Yongliang Huang, ${ }^{1,2}$ Zhiwei Sun, ${ }^{1}$ Chunyan Bao $\mathbb{D}^{1,3}$ Man Huang $\mathbb{D}^{1,3}$ Anyuan Li, ${ }^{1,3}$ \\ and Minghao Liu $\mathbb{I D}^{4}$ \\ ${ }^{1}$ College of Civil Engineering, Shaoxing University, Shaoxing, Zhejiang 312000, China \\ ${ }^{2}$ Zhejiang Nonferrous Metals Geological Exploration Bureau, Shaoxing, Zhejiang 312000, China \\ ${ }^{3}$ Key Laboratory of Rock Mechanics and Geohazards of Zhejiang Province, Shaoxing University, Shaoxing, Zhejiang 312000, China \\ ${ }^{4}$ State Key Laboratory of Frozen Soil Engineering, Cold and Arid Regions Environmental and Engineering Research Institute, \\ Chinese Academy of Sciences, Lanzhou, Gansu 730000, China
}

Correspondence should be addressed to Chunyan Bao; baochunyan1985@126.com

Received 6 November 2020; Revised 29 December 2020; Accepted 24 March 2021; Published 5 April 2021

Academic Editor: Guoyang Fu

Copyright @ 2021 Yongliang Huang et al. This is an open access article distributed under the Creative Commons Attribution License, which permits unrestricted use, distribution, and reproduction in any medium, provided the original work is properly cited.

\begin{abstract}
The Xiashan landslide, which is classified as a typical basalt platform landslide, is the most massive landslide in Zhejiang Province, China. Once sliding occurs, it will pose a severe threat to the life and property of downstream residents and the nearby section of HangzhouTaizhou Expressway. On the basis of the geological conditions, present situation, and latest monitoring data of the landslide, this study finds that rainfall is the main influencing factor, and the creep mode is the main prediction mode of its subsequent deformation. The rainfall statistics of the landslide area in the past 30 years show that the rainfall and rainfall frequency in the landslide area display an increasing trend. The probability of heavy rain with rainfall intensity of $100-250 \mathrm{~mm} /$ day in the landslide area is very high. On this basis, combined with the numerical analysis method, a finite element model of the slope considering rainfall and groundwater conditions is constructed to analyze the causes and failure mechanism of this landslide comprehensively. Results indicate that the maximum tensile stress at the top of the trailing edge under the natural state is $5.10 \mathrm{MPa}$, which is very close to the saturated tensile strength of rock mass. Thus, tensile cracks are easily generated and developed, thereby causing the failure mode to be the hydraulic driving type. Also, with the increase in rainfall intensity, the slope plastic strain increases and the slope plastic zone develops and extends until it is completely penetrated. When the rainfall intensity is more than $200 \mathrm{~mm} / \mathrm{day}$, the slope safety factor is close to unity, and the slope approaches a failure condition. Therefore, the landslide should be controlled through water treatment and integrated with engineering measures.
\end{abstract}

\section{Introduction}

The mechanical and hydraulic characteristics of rock joints have an important influence on the strength and stability of engineering rock mass $[1,2]$. Slope instability often occurs with the rapid development of infrastructure projects such as buildings, highways, railways, and bridges. Stability analysis is necessary for slope treatment. Whether subsequent processing will be carried out is decided in accordance with the results of stability analysis [3-5].

The traditional slope stability analysis method is qualitative analysis, which involves collecting meteorological, geological, hydrological, and deformation information of landslides through on-site surveys, geological prospecting, and landslide monitoring. Afterward, combined with engineering experience, the causes, influencing factors, and failure mechanisms of landslides are analyzed. With the rapid development of mechanics and computer technology in modern times, numerical simulation research methods have emerged, which can make full use of computers' superior computing performance and have the characteristics of accuracy and speed. Therefore, numerical simulation has become the mainstream trend of slope stability analysis today. To use the numerical analysis method, a numerical model needs to be established based on 
the relevant parameters obtained from the preliminary slope investigation and experiment. According to the stress-strain relationship, the numerical model can accurately calculate the real state of the slope under various conditions. The calculated results of slope displacement, stress, and strain can be expressed in the form of diagrams.

In recent years, many scholars have carried out a series of research on slope stability analysis. Cai [6], Wang [7], and Chen [8] collected information on the geological structure, material properties, and macroscopic deformation of a landslide by means of exploration, drilling, and Global Navigation Satellite System. They used the limit equilibrium method and finite element strength subtraction to research slope stability and found that water storage and rainstorm are closely related to landslide deformation. Zhou [9] et al. analyzed landslides in various ways, including field surveys, laboratory tests, and numerical simulations. They also believed that the intensity and duration of rainfall would affect the water pressure and shear strength of slopes. Rainfall significantly reduces the slope shear strength and increases the pore water pressure and soil weight. As a result, the slope stability is reduced. By studying the relationship between the internal stress state of the landslide caused by rainfall with time, Iverson [10], Calvello [11], and Zhou [12] established a new slope mathematical model that can consider seepage. On the basis of the model, they analyzed the influence of rainfall infiltration on the saturated state, pore water pressure, displacement rate, and safety factor of landslide under different conditions. Their research shows that water level fluctuation, permeability, and shear strength are the key factors that affect seepage field and slope stability. Iverson [13] used a newly developed model to simulate the Oso landslide in the state of Washington, USA. The model results show that liquefaction depended strongly on initial sediment porosity. Conte [14] used the material point method (MPM) to simulate the run-out process of the Maierato landslide in Southern Italy. They think that the high pore water pressure caused by the large distortions of the moving soil mass leads to the serious reduction of the shear strength of the soil.

The Xiashan landslide, which occurred in Xiashan Administrative Village, Huishan Town, Xinchang County, Zhejiang Province, China, took place in an old landslide hidden danger area that includes three villages, namely, Xiashan, Lishan, and Tangli villages. To this day, this area is still the most massive landslide in Zhejiang Province, with a landslide volume of 8.25 million $\mathrm{m}^{3}$, and is listed as a key monitoring geological hazard spot in the province. The Xiashan landslide has the typical characteristics of a basalt platform landslide $[15,16]$, and it exhibits intermittent activity because of many slides in the past.

At present, the landslide is unlikely to slide as a whole under normal conditions. However, heavy rain or long-term continuous rainfall may lead to local sliding and easily form barrier lakes at the foot of the slope [17]. The Shimen Reservoir, which is located on the west side of the landslide and has a storage capacity of approximately 4.5 million $\mathrm{m}^{3}$, will be affected. A risk of dam break exists and poses a severe threat to the life and property of the downstream residents and the nearby section of Hangzhou-Taizhou Expressway.
This study analyzes the different aspects of the landslide. First, the geological conditions, landslide status, cause analysis, and failure mechanism of the Xiashan landslide are investigated on the basis of the investigation results and relevant data obtained in 2019. Second, the recent half-year displacement and groundwater level monitoring data of the landslide are sorted. In addition, the historical rainfall data of Xinchang County in the past 30 years are collected, and the future rainfall situation is predicted. Third, a landslide numerical model considering rainfall and groundwater conditions is constructed using the finite element software Midas GTS NX. Lastly, stability analysis is performed in accordance with the calculation results, and prevention and treatment suggestions are proposed.

\section{Present Situation of the Xiashan Landslide}

The Xiashan landslide is located in a low mountainous and hilly area and has a maximum relative height difference of $386.5 \mathrm{~m}$. The considerable vertical height leads to an increased vertical geomorphic contrast, and the average natural slope of the terrain typically ranges within $25^{\circ}-40^{\circ}$. Given the early human farming activities, local areas form a multistep terrain in the longitudinal direction. The step height difference is mostly within the range of $8-20 \mathrm{~m}$, whereas a small part ranges within $30-35 \mathrm{~m}$. Both sides of the Shimen Reservoir on the west side of the landslide are violently cut down by the river. A V-shaped valley landform is formed, and the undercut depth is generally larger than $100 \mathrm{~m}$ (Figure 1).

According to the drilling results, the rock and soil layers in the landslide area are divided into the following 15 layers from top to bottom (Figure 2): (1) silty clay layer containing crushed stones, (2) gravel layer containing cohesive soil, (3) basalt, (4) pebble subclay layer, (5) basalt, (6) sandy clay, (7) clay rock, (8) layer containing peat soil, (9) clay rock containing gravel, (10) layer containing peat soil, (11) basalt, (12) gravelly clay rock, (13) basalt, (14) silty clay layer containing gravel sand, and (15) tuff intercalated with tuffaceous sandstone.

The fracture developments of the Quaternary gravel layer, sedimentary rock containing sand (gravel) layer, and basalt layer in the landslide area lead to good permeability. The main sources of groundwater recharge are atmospheric precipitation and interlayer overflow recharge channels. The irrigation water recharge through channels and valley water recharge is the second source of replenishment. The hydraulic connection among aquifers is excellent. Groundwater is discharged from the surface in the form of spring water (scattered flow, gushing water, and seepage water) at the scarps, contact surface between aquifers and waterproof layer, front edge of the landslide, low-lying terrains, and landslide cracks.

Basalt joints and fissures developed due to the influence of the geological structure cut the rock mass under the effect of subsequent weathering. The joints and fissures along the slope direction greatly influence the stability of the landslide. The crust of the landslide area is raised and lowered repeatedly by the neotectonic movement. As a result, the rock 


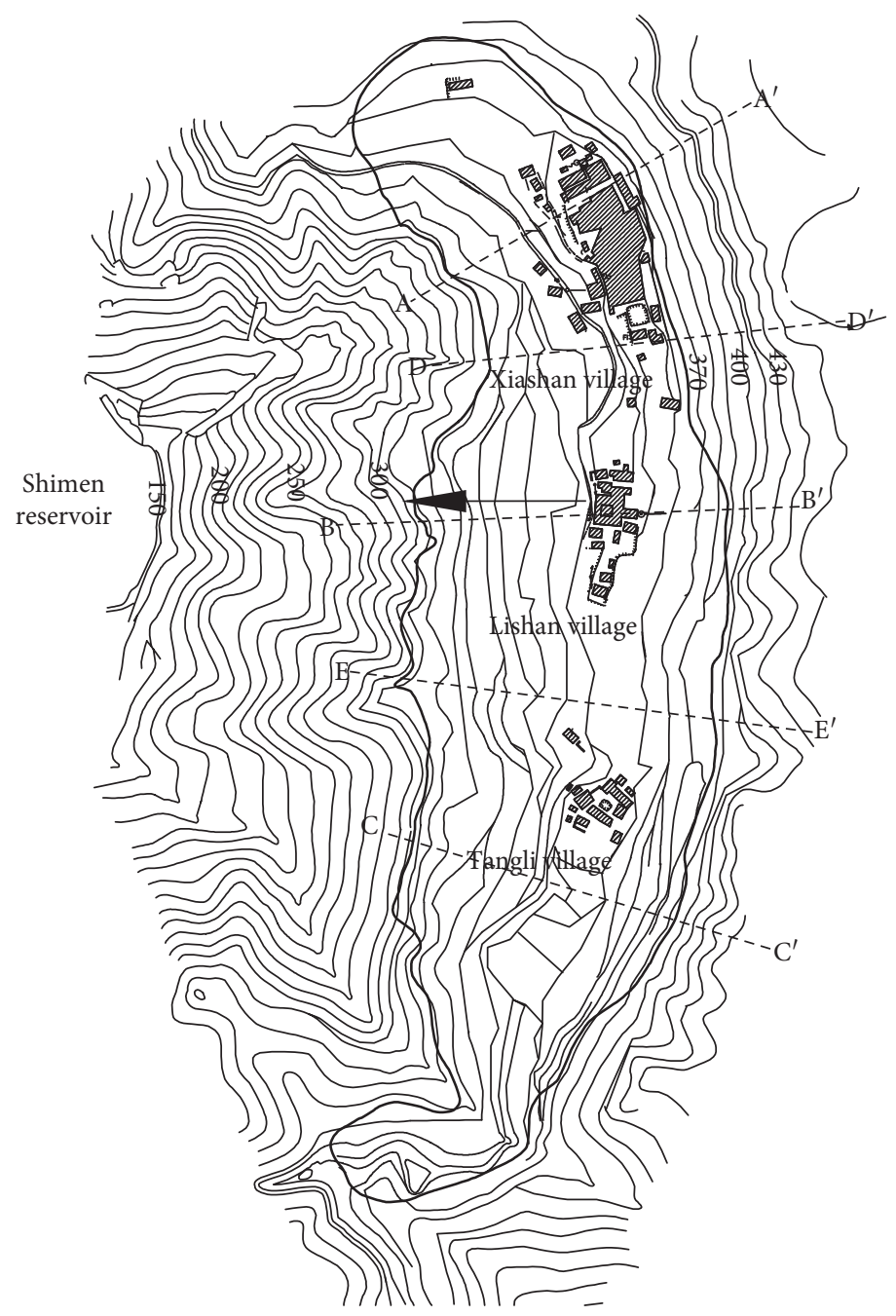

FIgUre 1: Planar graph of Xiashan landslide.

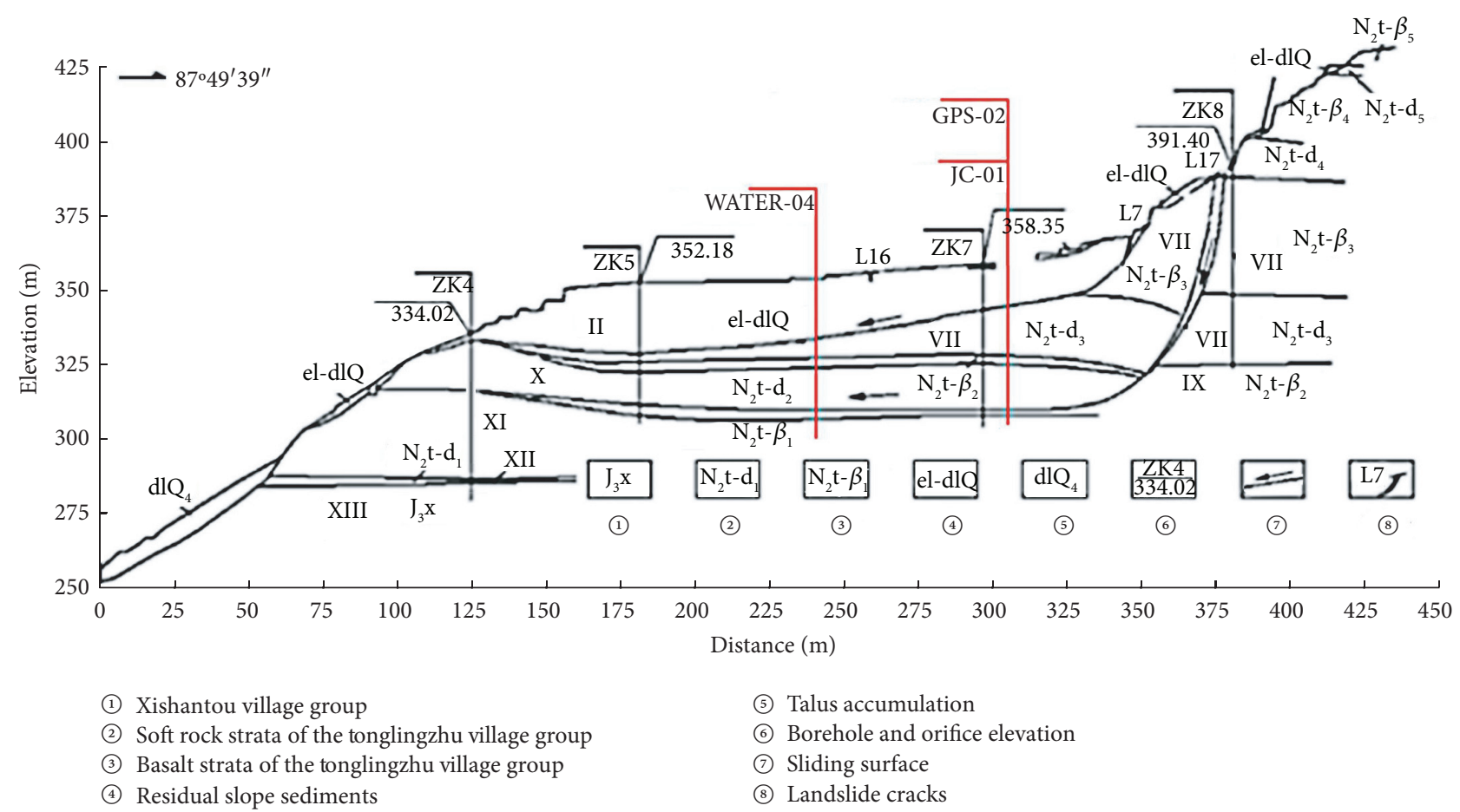

FIGURE 2: Engineering geological map of typical section. 
formations in the area often exhibit topographic inversion and many different lithological types. In addition, the alternating occurrence of eruptive and sedimentary layers always occurs, which is unfavorable to the stability of the landslide.

The cracks in the landslide area are vertically and horizontally developed into a grid shape. These cracks can be divided into tension and shear cracks depending on the causes. The width of the cracks is $0.3-3.0 \mathrm{~m}$; such cracks mostly form steps, depressions, and ditches. Two sliding surfaces mainly control the Xiashan landslide. The shallow sliding surface is located at the contact point between gravel and silty clay, whereas the deep sliding surface is located at the contact point between the layer containing peat soil and the moderately or strongly weathered basalt. The trailing edge of the two sliding surfaces has a large inclination angle with cracks at the top, allowing the surface water to easily seep down. The middle part of the edge is relatively flat.

The residents of the original Xiashan, Lishan, and Tangli villages have been relocated, and the original landslide area is now completely restored into dry land. Most of the houses in the area have been demolished. The engineering activities in the site mainly include human farming activities on the surface of the slope, which can promote the infiltration of surface water on the landslide to a certain extent. The overall level of human engineering activities is average.

\section{Causes and Failure Mechanism}

3.1. Cause Analysis. Historical records and statistics and monitoring data of the seismic stations [18] indicate that 34 perceptible earthquakes occurred from the year of Yongyuan of the Han Dynasty (89 AD) to 1990. The common earthquakes had a magnitude of less than 4.75 with a weak intensity and low frequency, and no disaster occurred. The peak acceleration of the earthquake in Xinchang County was less than $0.05 \mathrm{~g}$, and the corresponding basic earthquake intensity was lower than VI degrees, which belongs to the stable crustal area [19].

Three large-scale landslide activities have occurred since 1958. Rainfall is the dominant factor, and human intervention is the secondary factor. In terms of causes, the main factors include three aspects. First, rainwater rapidly converges from the former to the latter due to the large difference in the height between the middle and trailing edges of the slope. The terrain in the middle of the slope is relatively flat, and the surface water gathered in this area will accumulate and infiltrate. Both have adverse effects on slope stability. Second, the Quaternary gravel layer, sedimentary rock containing sand (gravel) rock layer, and basalt fissures have good permeability. The infiltration of rainwater loosens and softens the rock and soil, thereby resulting in a rapid decline in their cohesion forces and making the area prone to plastic deformation. Lastly, the rise in the water level at the trailing edge of the slope produces a tremendous hydrostatic pressure under the influence of rainfall. The water level difference will convert the hydrostatic pressure into an equivalent hydrodynamic pressure, which is conducive to the sliding of the sliding surface. As previously mentioned, the human engineering activities in the landslide area are the secondary factor. Soil loosening caused by human plowing greatly helps the surface water infiltrate the landslide and promotes the development of the landslide from the other side.

3.2. Failure Mechanism Analysis. The failure mode of the Xiashan landslide belongs to the consequent layer sliding failure $[20,21]$. In accordance with the mechanical mechanism of deformation and failure, the consequent layer sliding failure of the general rock slope can be divided into two modes: sliding tensile cracking type and hydraulic driving type.

Historical exploration data of the Xiashan landslide indicate that the cracks in the landslide are relatively developed, and the landslide mass is cut into a grid shape. Cracks appeared in every part of the landslide a few days after the landslide slipped on July 30, 1989. These cracks have a relatively short development time, and their width, length, and depth are relatively small. Moreover, these cracks have a weak effect on the stability of the landslide. The landslide is mainly controlled by the shallow weak surface in the slope. Given that the weak surface is located at the contact point of different rock layers, the cohesive force of the nearby rock and soil is small. Therefore, the shear strength of the weak surface is greatly affected by the internal friction angle. The inclination angle of the shallow weak surface is greater than its equivalent internal friction angle, and the sliding force of the sliding body is greater than its shear strength. In addition, the toe of the slope is a free surface, thus causing the slope to be likely to form tensile cracks at the trailing edge due to creep, which will lead to instability and failure. In such a case, the failure mode of the Xiashan landslide belongs to the sliding tensile cracking type (Figure 3 ).

During large-scale survey and mapping in 2003, 24 representative cracks were investigated, including tension cracks, bulging cracks, shear cracks, and other cracks with typical stress characteristics. The Xiashan landslide is characterized by the appearance of new cracks or the widening of previous cracks in the landslide body. The development degree of the tensile cracks on the trailing edge of the landslide body gradually increases over time. The width, length, and depth of the cracks significantly increase; the depth of the crack is more than $50 \mathrm{~m}$ and connects with the deep weak surface in the slope. Given that the inclination angle of the deep weak surface is less than its equivalent internal friction angle, the landslide can maintain a relatively stable state in its natural state even if the toe of the slope is in the air. The deformation and failure of a rock slope are not only related to the inclination shape, thickness, and mechanical properties of the weak surface, but are also affected by the groundwater and water content of the rock and soil in the slope. The vertical joints and fissures of basalt in the eruptive layer of the Pliocene Sheng County group are developed and easily lead to the downward infiltration of surface water. During rainfall, especially heavy ones, the surface runoff at the trailing edge of the slope flows into the cracks. A large amount of precipitation seeps into the sliding 


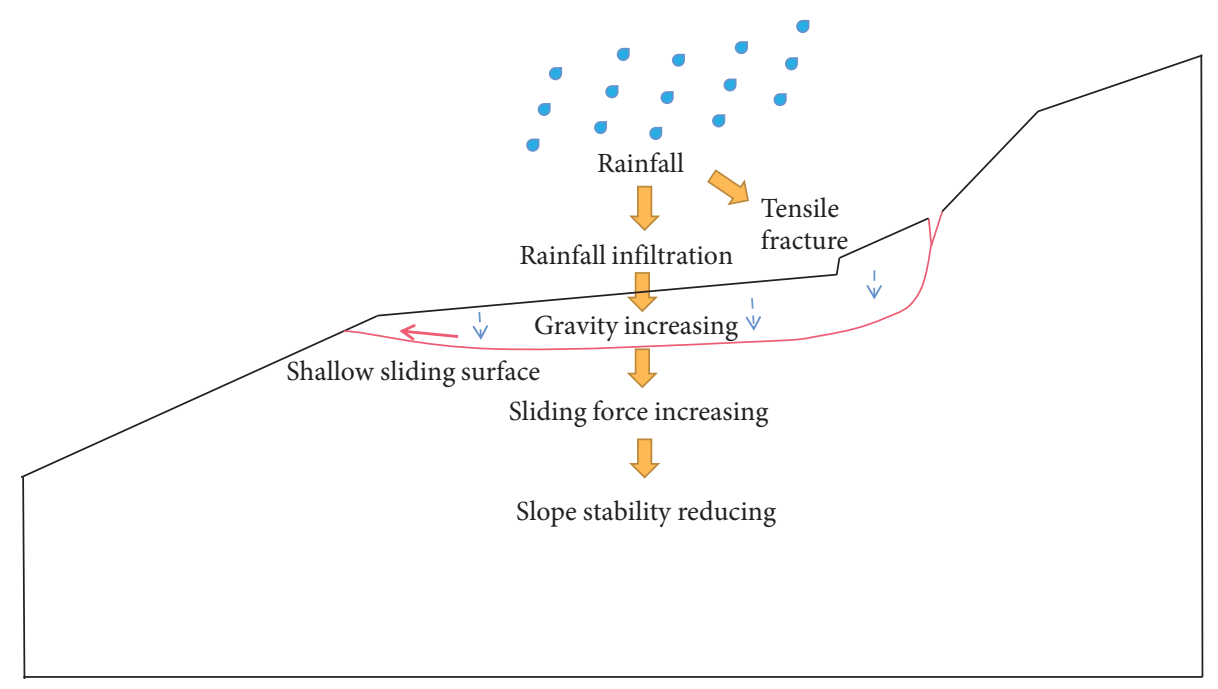

FIgURE 3: Schematic of sliding tensile cracking type.

mass and moves the aquifer into the saturation state. As a result, rock and soil particles will float, the spacing between the rock and soil particles will increase, and the shear strengths of the rock and soil will be reduced. After the water saturation level of each aquifer increases, the phreatic aquifer becomes a phreatic-confined or confined aquifer. Consequently, the bulk density of the rock and soil rapidly increases, the water buoyancy force rises, and the antisliding ability abruptly decreases. In addition, the slope of the sliding bed formed by the cracks at the trailing edge of the landslide is exceptionally steep. With the increase in rainfall intensity, the height of the water head in the cracks at the trailing edge of the landslide increases. The hydrostatic pressure caused by the rise in groundwater level, the hydrodynamic pressure formed by groundwater flow (i.e., uplift pressure), and the seepage pressure of the sliding zone (i.e., drag force) will also increase. When the rainfall intensity reaches a certain critical value, the sum of the driving forces (sliding force) generated by gravity and hydrostatic, hydrodynamic, and seepage pressures becomes greater than the weakened shear strength (antisliding force). As a result, the landslide slips and loses stability. At this time, the failure mode of the Xiashan landslide changes from the sliding tensile cracking type to the hydraulic driving type (Figure 4).

3.3. Deformation Prediction. An analysis of the landslide causes and failure mechanism shows that creep deformation is the main subsequent deformation mode of the Xiashan landslide. The organic soil and low-strength clay rock in the Tonglingzhu Village sedimentary section of the Pliocene Sheng County group are the control sliding surfaces of the landslide. The stability and deformation of the landslide are closely related to the groundwater content in the landslide body. In general, directly replenishing the groundwater in the deep slide through low-intensity, short-term rainfall is difficult. However, when the rainfall intensity is high or long-term rainfall occurs, the sliding surface softens and the saturation of the sliding body increases with the continuous infiltration of surface water, thereby resulting in sliding deformation.
Considering the sizeable transverse width of the landslide and the fluctuation change of the buried depth of the sliding surface, the possibility of continuous and integrated sliding in later period is minimal. When the emergency balance is unbalanced, the sliding mass in the entire landslide area is mainly segmented and discrete. The inclination angle of the gliding section of the leading edge is gentle, and the overall slip amount is small.

\section{Monitoring Results and Rainfall Statistics}

4.1. Analysis of Monitoring Results. Twenty years have passed since the major sliding of the Xiashan landslides occurred in 2001 due to continuous rainfall. To obtain an accurate understanding of the current situation of the landslide, this study collates and summarizes the monitoring data of deep displacement, surface displacement, rainfall, and groundwater level of the relevant monitoring points near the B-B section of the Xiashan landslide for half a year.

The accumulated displacement at $30.5 \mathrm{~m}$ below the JC-01 deep displacement monitoring point for the Xiashan landslide in the first half of 2020 is shown in Figure 5. The cumulative displacement data fluctuate between -0.2 and $0.2 \mathrm{~mm}$ with time. Considering the error factors, such as the accuracy of the monitoring instruments and difficulty of field monitoring, no deep displacement is observed at $30.5 \mathrm{~m}$ below the monitoring point. The buried depth of the WATER-04 groundwater level monitoring point is relatively stable in the first half of 2020. The average depth of the water level is $34.26 \mathrm{~m}$. As shown in Figure 6, April 2020 experienced 6 days of rain, with a total rainfall of $150 \mathrm{~mm}$ and a maximum daily rainfall of $45 \mathrm{~mm}$. The cumulative displacement data range of the GPS-02 surface displacement monitoring points in April 2020 is $1.94-3.56 \mathrm{~mm}$. The total surface slip in April is $1.6 \mathrm{~mm}$, and the displacement rate is $0.05 \mathrm{~mm} /$ day. The overall trend is increasing with time.

Observing Figure 6, we find that the surface displacement curve has five rapid-rise periods. The rainfall intensity is less than $50 \mathrm{~mm} /$ day; thus, the acceleration of the ground 


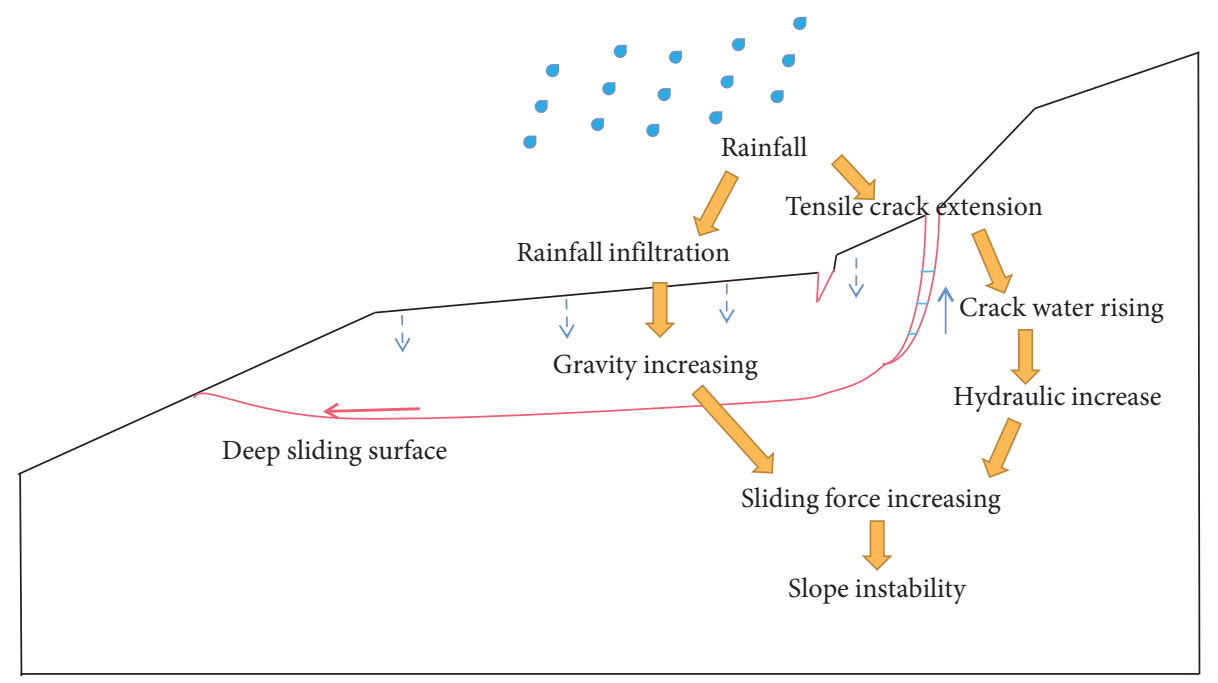

Figure 4: Schematic of hydraulic driving type.

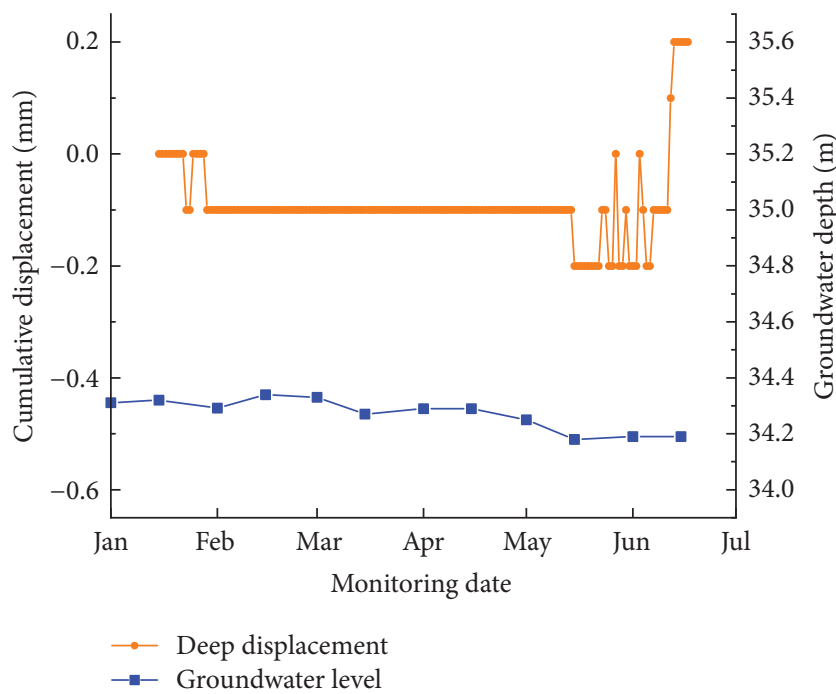

Figure 5: Deep displacement and groundwater level from January to June 2020.

surface displacement caused by rainfall intensity is similar. Notably, these five rise periods all took place on the day or the next day of rain, thereby showing that slope deformation and rainfall have a very close relationship. The infiltration of rainwater can make the surface slope loose and softened, thus causing the slope cohesion to decrease rapidly, which in turn accelerates the surface displacement of the landslide. After a short increase in speed, with the end of rainfall, the water in the surface and shallow soil is discharged in the form of spring water (or water gushing or seepage) at the front edge of the landslide, low-lying terrain, and landslide cracks. The slope returns to its normal state. The surface displacement rate of the landslide decreases until it reaches a relatively slow value. A small amount of rainfall has little influence on landslide deformation. At a low rainfall intensity, the depth of rainwater infiltration is limited, with almost no impact on groundwater. Considering that no other water supply is available in the landslide area, the

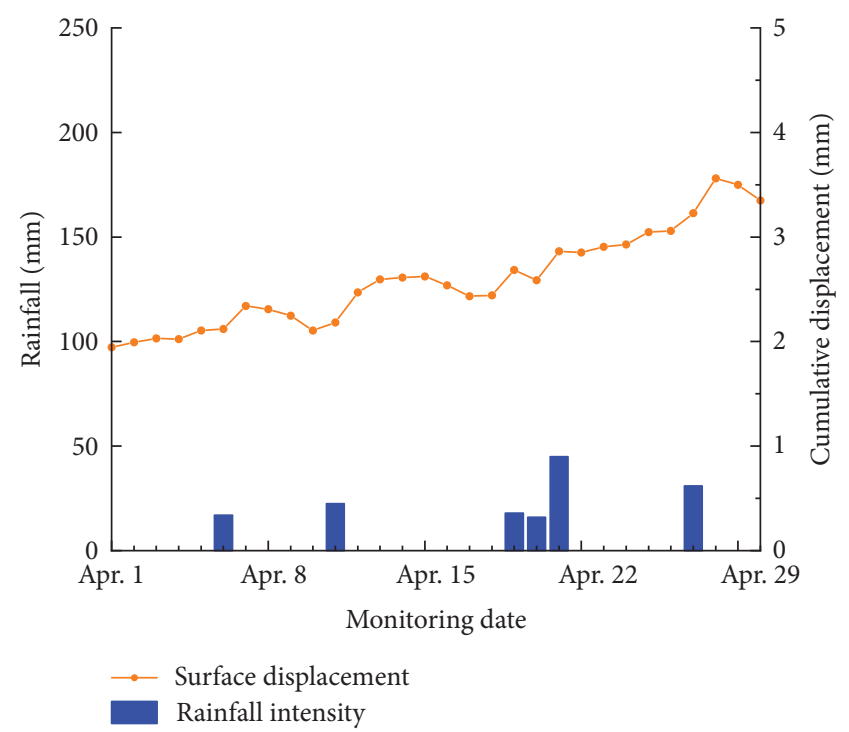

Figure 6: Surface displacement and rainfall in April 2020.

change of groundwater level curve is small or even slightly decreased, thereby leading to no deep displacement of landslides, and the curve in Figure 6 fluctuates around 0.

On the basis of the above analysis, the Xiashan landslide is relatively stable due to the small rainfall and the low rainfall intensity in the first half of 2020 . However, it has a slipping trend and is in a creep state. During summer or when the area is affected by typhoons, the greater rainfall intensity will further infiltrate into the groundwater. The deep displacement of the landslide caused by it may lead to speed sliding of the landslide.

4.2. Historical Statistics and Prediction of Rainfall. The rainfall in Zhejiang Province has been dominated by erosive rainfall for the past 30 years. The risk of soil erosion caused by rainfall is likely to increase significantly [22, 23]. Typhoons are one of the main factors that contribute to the surge in rainfall. The rainstorm brought by the typhoon is 
highly sensitive to low-consolidation and unsaturated soil. Under the action of rapid infiltration, disasters, such as landslides and debris flows, can easily occur.

Xinchang County is relatively affected by typhoons. Statistics reveal that heavy rain (daily rainfall $>100 \mathrm{~mm}$ ) in Xinchang County lasts for 12 days, with the obvious effects of a typhoon observed in six days. Table 1 shows that the average daily rainfall in six days is $139.53 \mathrm{~mm}$, and the process rainfall can reach $200-500 \mathrm{~mm}$. Typhoon Lekima (1909) in 2019 exerted the most significant effect on Xinchang County. The rainfall reached $32 \mathrm{~mm}$ within three hours, and the daily rainfall reached $221 \mathrm{~mm}$.

Research on extreme precipitation events in Xinchang County indicates that the frequency and intensity of such events display an increasing trend under the background of global warming (Figures 7 and 8). On the basis of the $221 \mathrm{~mm}$ rainfall from 11:00 a.m. on August 9, 2019, to 11:00 a.m. on August 10, 2019, and a rainfall tendency rate of $1.03 \mathrm{~mm} /$ year, the maximum daily rainfall is expected to reach $251.9 \mathrm{~mm} /$ day in 30 years. The existing waterproof and drainage facilities cannot adapt to the problem of the annually increasing rainfall.

\section{Analysis of Numerical Result}

5.1. Numerical Model and Related Parameters. The curved surface flow function in Midas GTS NX can be used to transform the boundary conditions of the water head and flow in the rainfall analysis. This function is applicable to the mandatory definition that the surface flow is equal to the rainfall intensity. When the ability of the soil surface to absorb rainfall is greater than the rainfall intensity, the soil layer can absorb the rainfall. Otherwise, only part of the rainfall is absorbed by the surface in accordance with the absorption capacity of the soil layer; the rest of the rainfall will flow along the surface of the ground.

The typical section, which is consistent with the main sliding direction of the Xiashan landslide, is selected as an example and analyzed using the finite element strength reduction method. This method does not need to assume the shape and position of the sliding surface, and the unstable sliding surface and corresponding stability safety factor of the slope can be automatically obtained by the program [23-27]. The Mohr-Coulomb model is used to simulate the soil behaviour. In order to emphasize the shear effect of the soil, the dilatancy is not considered. The physical and mechanical parameters of the landslide, groundwater parameters, and rainfall parameters used in the model are determined in accordance with survey results and relevant landslide data (Table 2). The calculation layering, grid division, and boundary constraints of the rock and soil are shown in Figure 9. In order to facilitate the calculation, the soil layers based on Figure 2 are combined and simplified in the modeling process. Six working condition models are set to examine the influence of groundwater and rainfall on slope stability.

Condition 1: gravity + normal groundwater level

Condition 2: gravity + normal groundwater level+ rainfall intensity $50 \mathrm{~mm} /$ day for 1 day
Condition 3: gravity+ normal groundwater level + rainfall intensity $100 \mathrm{~mm} /$ day for 1 day

Condition 4: gravity + normal groundwater level + rainfall intensity $150 \mathrm{~mm} /$ day for 1 day

Condition 5: gravity+ normal groundwater level + rainfall intensity $200 \mathrm{~mm}$ /day for 1 day

Condition 6: gravity + normal groundwater level + rainfall intensity $250 \mathrm{~mm} /$ day for 1 day

5.2. Simulation Results and Analysis. Figure 10 shows the $X$ direction stress (tensile stress) diagram obtained from the static analysis in the natural state (working condition 1). In the figure, the stress at the top of the trailing edge is the maximum $(5.10 \mathrm{MPa})$. The stratum is the third eruption layer with basalt lithology, with a saturated tensile strength of $5.33 \mathrm{MPa}$. The tensile stress at the top of the trailing edge is close to its saturated tensile strength in the natural state. In case of heavy rainfall, the tensile stress will further increase beyond its saturated tensile strength. Tensile cracks will then appear at the top of the trailing edge, and these cracks will gradually increase with time and affect the stability of the landslide. This observation is consistent with the conclusion regarding the previously analyzed landslide failure mechanism.

Figures 11-16 depict the equivalent plastic strain diagrams of the slopes under the six working conditions. The major strain inside the sliding body is concentrated on the contact zone of shallow sliding and deep creeping. The slope is mainly controlled by two sliding surfaces. Under the action of rainfall and groundwater, the rock and soil around the two sliding surfaces are prone to plastic deformation. This deformation is relatively apparent in the middle and trailing edges of the landslide. The maximum and average thicknesses of the sliding body are approximately 60.0 and $34.25 \mathrm{~m}$, respectively. The rainfall intensity significantly affects the plastic zone of the slope. With the increase in rainfall intensity, the plastic zone of the slope develops and extends until it is completely penetrated, and the rock and soil masses in this zone are prone to violent sliding.

Table 3 and Figure 17 suggest that the slope safety factor is inversely proportional to the rainfall intensity and therefore decreases with the increase in the latter. The monitoring data in the first half of 2020 show that the daily rainfall is less than $50 \mathrm{~mm}$, which corresponds to the numerical model of working conditions 1 and 2. A comparison between Figures 11 and 12 shows that the plastic strain is relatively large on the slope surface and decreases with the increase in depth. As the rainfall intensity increases from $0 \mathrm{~mm} /$ day to $50 \mathrm{~mm} /$ day, the plastic strain of the slope increases. At the same time, the plastic strain zone of the slope also expands and gradually penetrates near the shallow sliding surface. However, it is still concentrated in the upper part of the entire landslide area because the rainfall is relatively light, and the rainwater can only infiltrate the shallow soil. The increase in shallow soil saturation leads to the decrease in shear strength and slope safety factor. Then, the slope deformation rate increases. At this time, the slope is mainly controlled by the shallow sliding surface. This finding is the same as the conclusion obtained by 
TABLE 1: Statistics of the typhoons that affect the rainfall in Xinchang County from 1990 to 2019.

\begin{tabular}{lccc}
\hline Typhoon number & Name of typhoon & Start and end dates & Daily rainfall (mm) \\
\hline 9015 & Abe & $1990 / 8 / 31-1990 / 9 / 1$ & 110.3 \\
9219 & Ted & $1992 / 9 / 23-1992 / 9 / 24$ & 125.8 \\
0716 & Krosa & $2007 / 10 / 7-2007 / 10 / 8$ & 134.7 \\
1323 & Fitow & $2013 / 10 / 7-2013 / 10 / 8$ & 134.9 \\
1909 & Lekima & $2019 / 8 / 10-2019 / 8 / 11$ & 221 \\
1918 & Mitag & $2019 / 10 / 2-2019 / 10 / 3$ & 101.5 \\
\hline
\end{tabular}

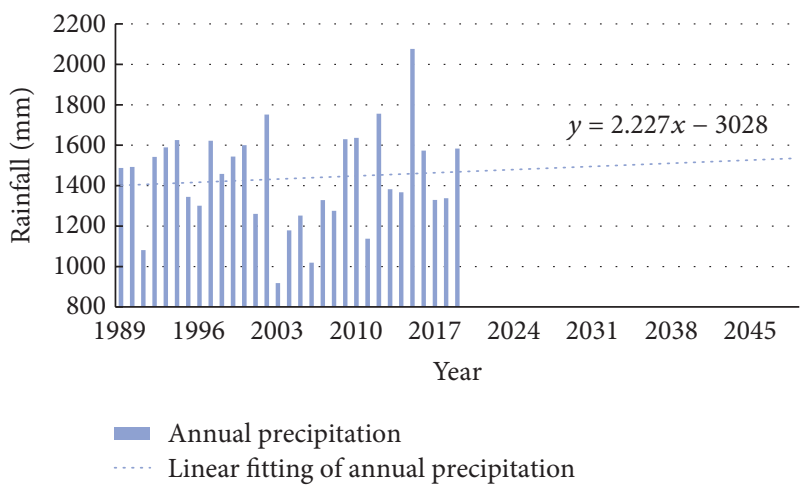

Figure 7: Annual precipitation and forecast in Xinchang County.
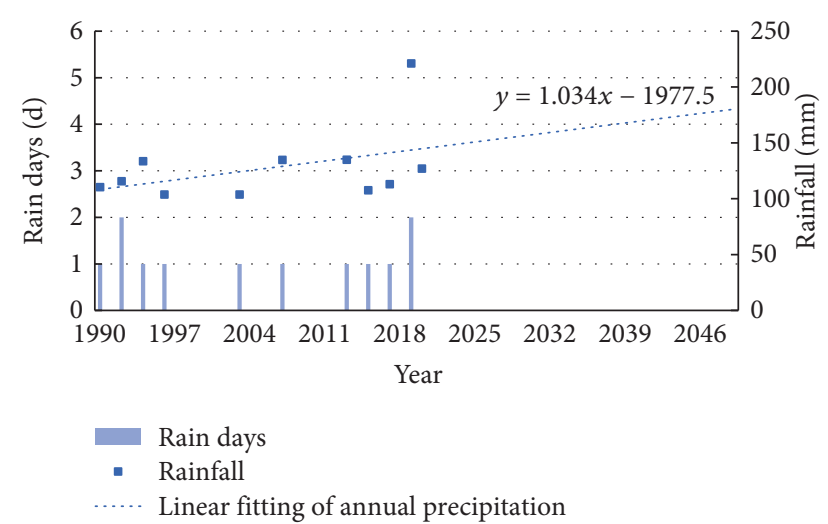

Figure 8: Rainfall situation and heavy rain forecast in Xinchang County over the years.

analyzing the monitoring data. When the rainfall intensity increases from $50 \mathrm{~mm} /$ day to $100 \mathrm{~mm} /$ day, the rainwater infiltration rate increases. The increase rate of deep soil saturation elevates, and the overall shear strength of the slope significantly decreases. In addition, the decline rate of the slope safety factor is at maximum. The critical sliding surface of the slope transits from the shallow layer to the deep layer. When the rainfall intensity increases from $100 \mathrm{~mm} /$ day to $250 \mathrm{~mm} /$ day, the rainwater penetration rate and infiltration speed reach the maximum. Shallow and deep soils tend to be saturated, and the shear strength is close to the minimum value. The decreasing trend of the slope safety factor is relatively gentle, and the slope is mainly controlled by the deep sliding surface.

The slope safety factor ranges from 1.042 to 1.151 . When the rainfall intensity is less than $200 \mathrm{~mm}$ /day, the slope safety factor is less than 1.15, and the slope is in a relatively stable stage. Otherwise, the slope safety factor is close to unity $(\mathrm{SF}=1)$, and the slope approaches a failure condition. Therefore, the landslide is generally in a stable state. In the case of rainfall, the slope is between unstable and relatively stable states. In conclusion, the slope is in the state of intermittent pushing creep. The source of the intermittent thrust is closely related to the increase in soil saturation caused by rainfall.

\section{Prevention and Treatment Suggestion}

The principle that should be followed in slope treatment is to detect problems as early as possible, prioritize prevention, identify the situation and treat it comprehensively, strive to find a radical solution, and avoid the possibility of future issues. Moreover, the solution should focus on water treatment. The prevention and treatment suggestions (Figure 18) are enumerated below:

(1) The landslide should be continuously monitored, and more targeted monitoring items should be added, such as crack monitoring, stress monitoring, and microseismic monitoring. Establishing a network automatic real-time monitoring system facilitates the rapid extraction of various data in the database analysis, and an early warning model of dynamic disaster needs to be constructed. In accordance with the reliability measurement standard of stability evaluation, alarm valves can be set to provide accurate alarms when the area is unattended.

(2) Large cross section intercepting ditches can be excavated on the stable stratum outside the slope top to effectively prevent external surface water from entering the landslide area. Moreover, the number of drainage ditches on the landslide surface can be increased and the cross-sectional area of drainage ditches can be enlarged to accelerate the discharge of surface water. The layout density of underground drainage facilities, such as seepage ditches, blind ditches, drainage holes, and water collection wells, should be increased. The maintenance and repair of the waterproof and drainage reinforcement facilities should be conducted on a regular basis.

(3) Waterproof materials with strong adhesion features should be utilized to repair cracks on the slope surface. Also, restoring vegetation on the wasteland and setting up grid protection on the steep air face can enhance the slope stability. 
TABLE 2: Relevant parameters of the rock and soil.

\begin{tabular}{lccccc}
\hline $\begin{array}{l}\text { Structural } \\
\text { layer }\end{array}$ & $\begin{array}{c}\text { Elastic modulus } E \\
(\mathrm{MPa})\end{array}$ & $\begin{array}{c}\text { Poisson's ratio } \\
\nu\end{array}$ & Volumetric weight $\gamma\left(\mathrm{kN} / \mathrm{m}^{3}\right)$ & $\begin{array}{c}\text { Cohesion intercept } c \\
(\mathrm{kPa})\end{array}$ & $\begin{array}{c}\text { Angle of internal friction } \\
\varphi\left({ }^{\circ}\right)\end{array}$ \\
\hline Sliding mass & 15 & 0.33 & 19.7 & 10.3 & 12.4 \\
Strata III-IX & 4000 & 0.23 & 21 & 300 & 50 \\
Stratum X & 5000 & 0.21 & 22 & 400 & 50 \\
\hline
\end{tabular}

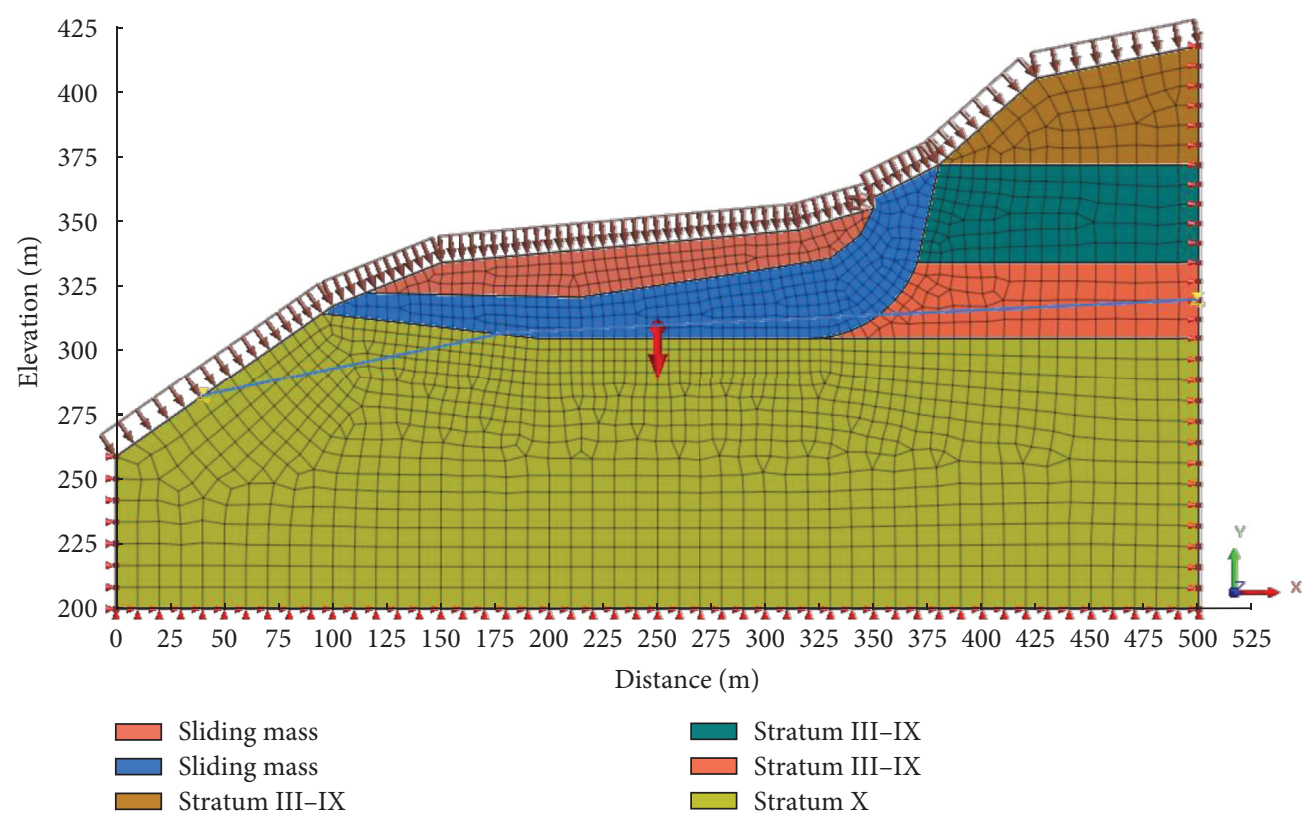

FIGURE 9: Landslide calculation model.

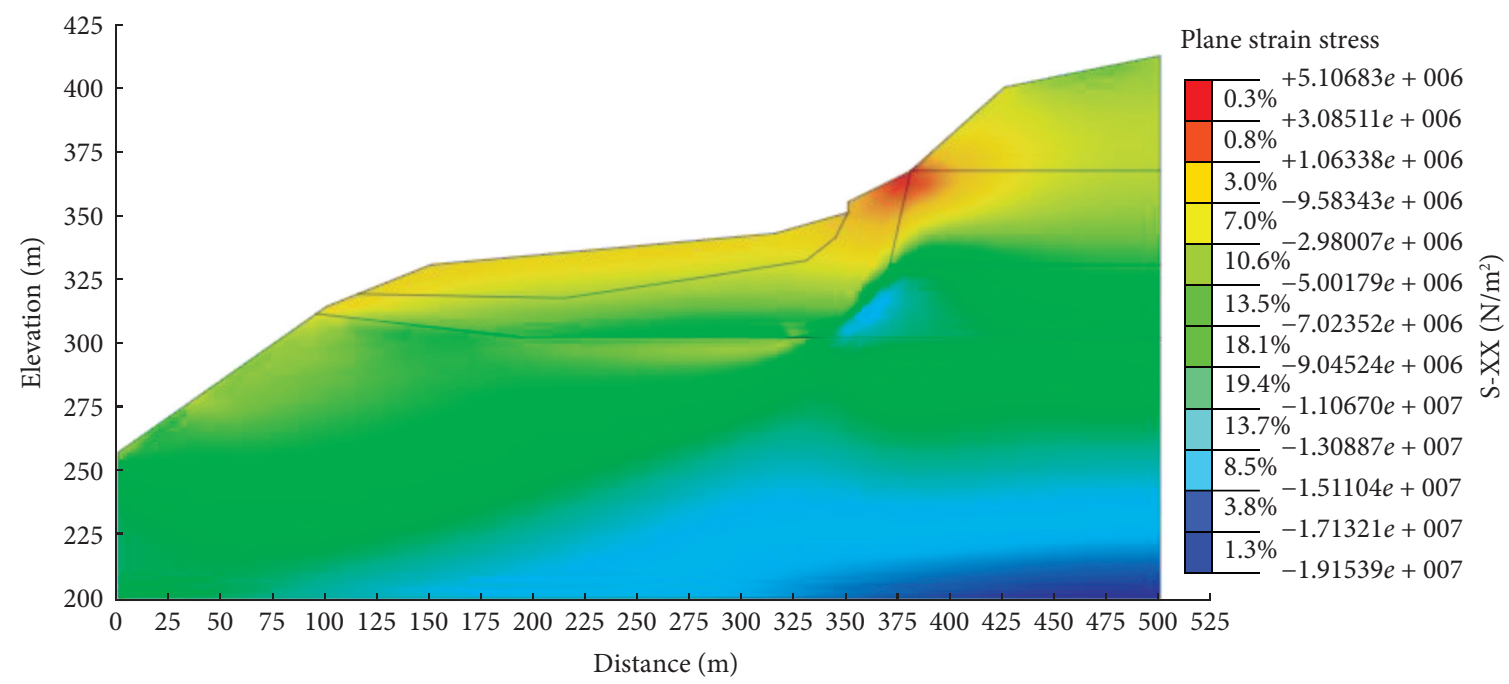

Figure 10: $X$-direction stress diagram of working condition 1. 


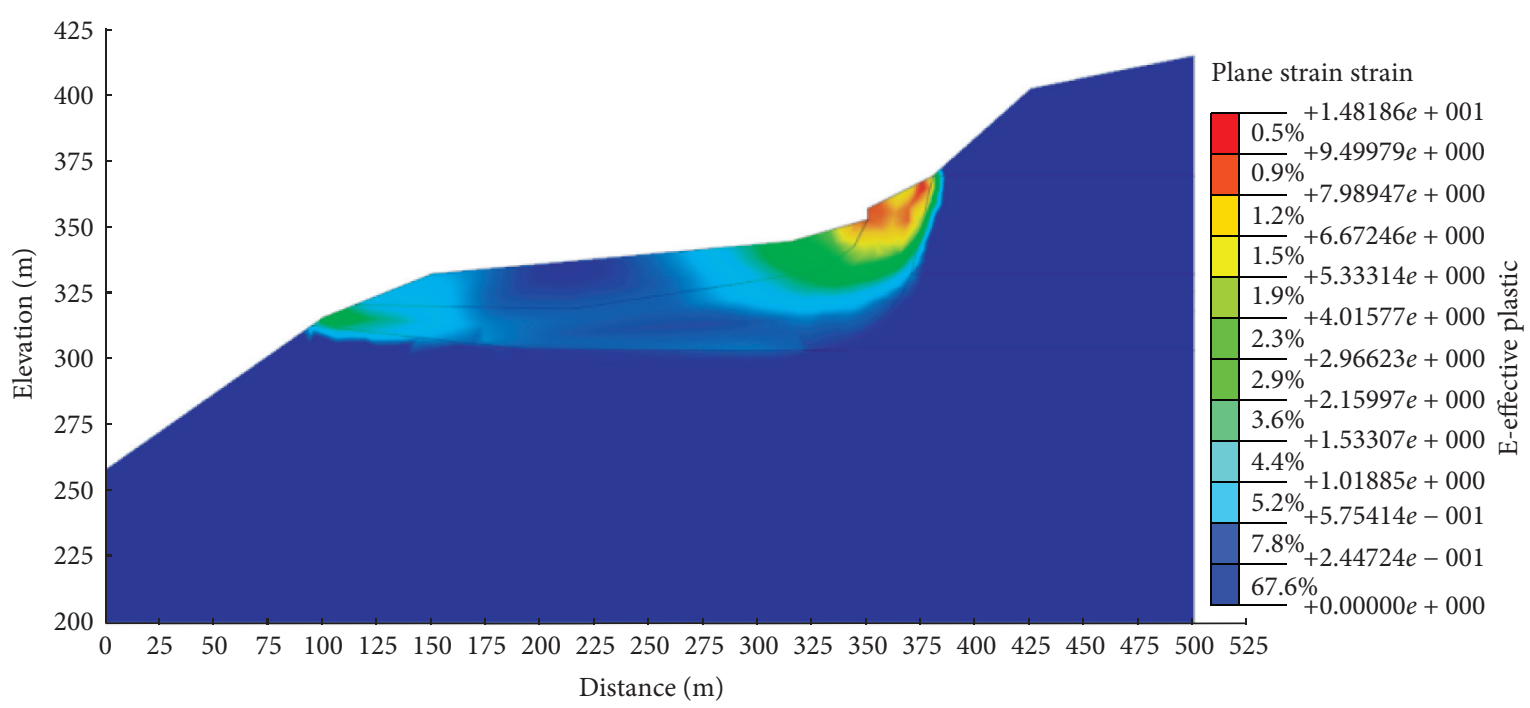

FIGURE 11: Plastic strain diagram of working condition 1.

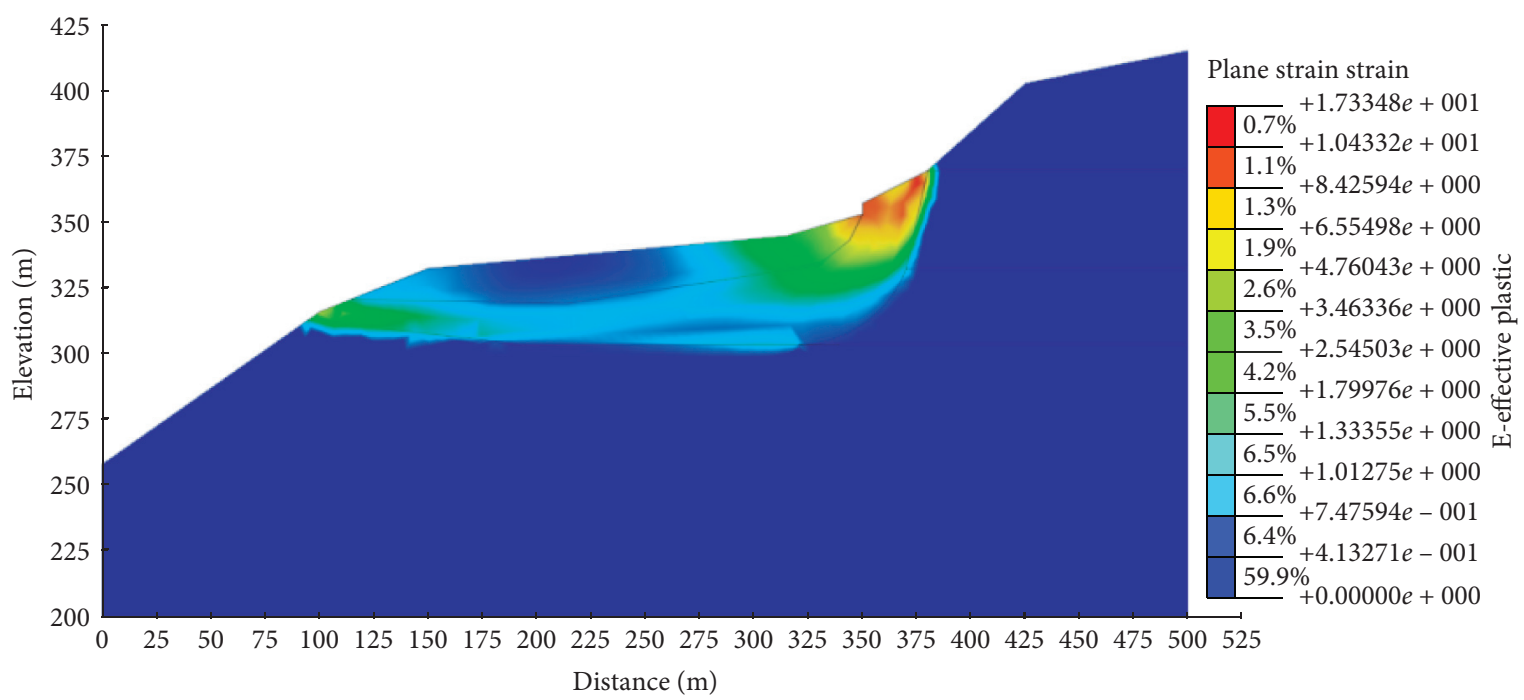

Figure 12: Plastic strain diagram of working condition 2.

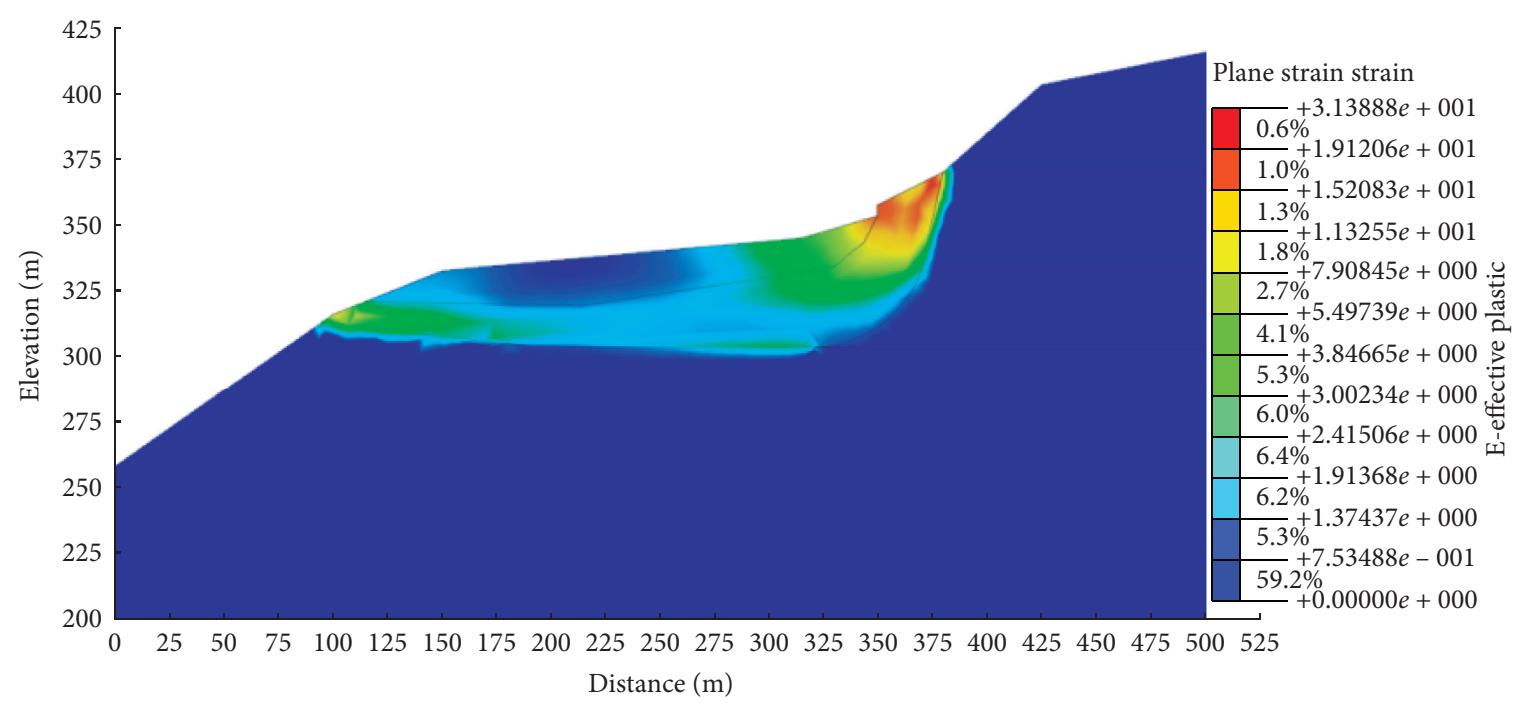

FIGURE 13: Plastic strain diagram of working condition 3. 


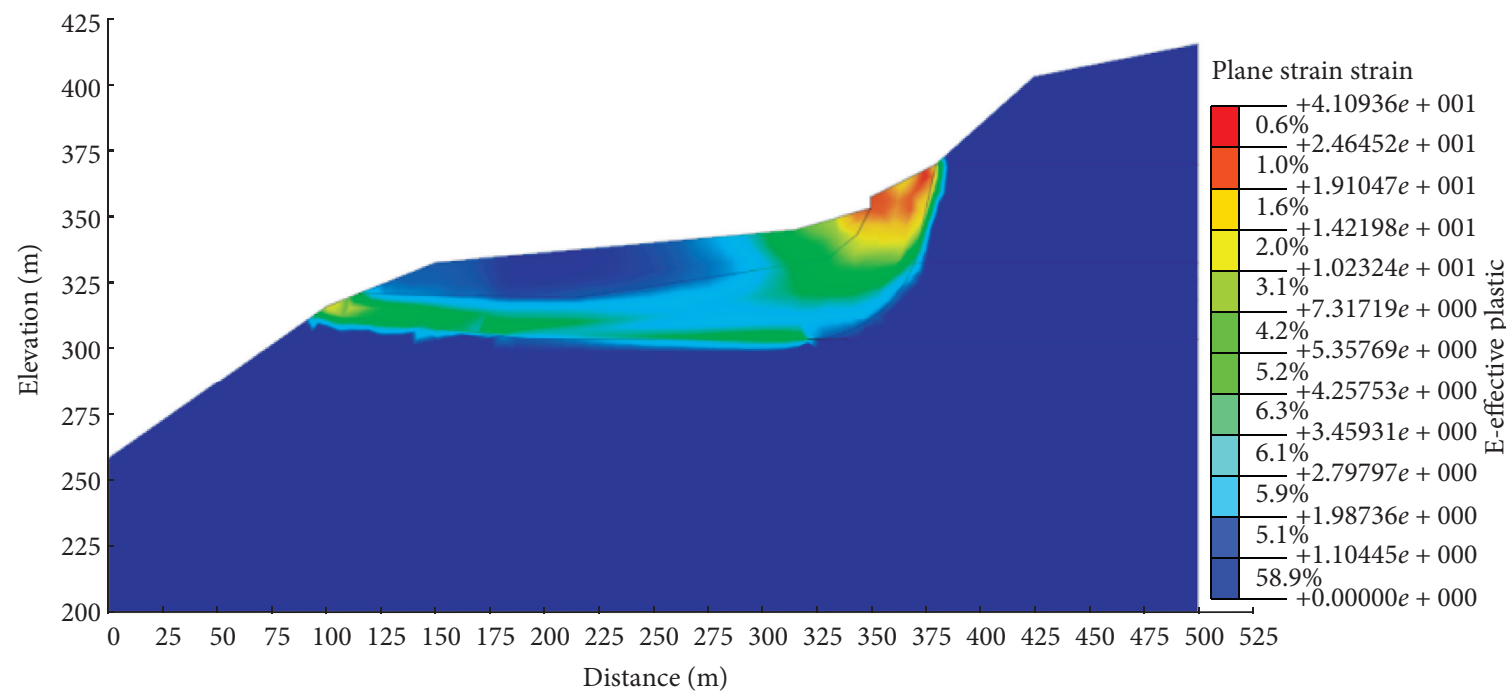

Figure 14: Plastic strain diagram of working condition 4.

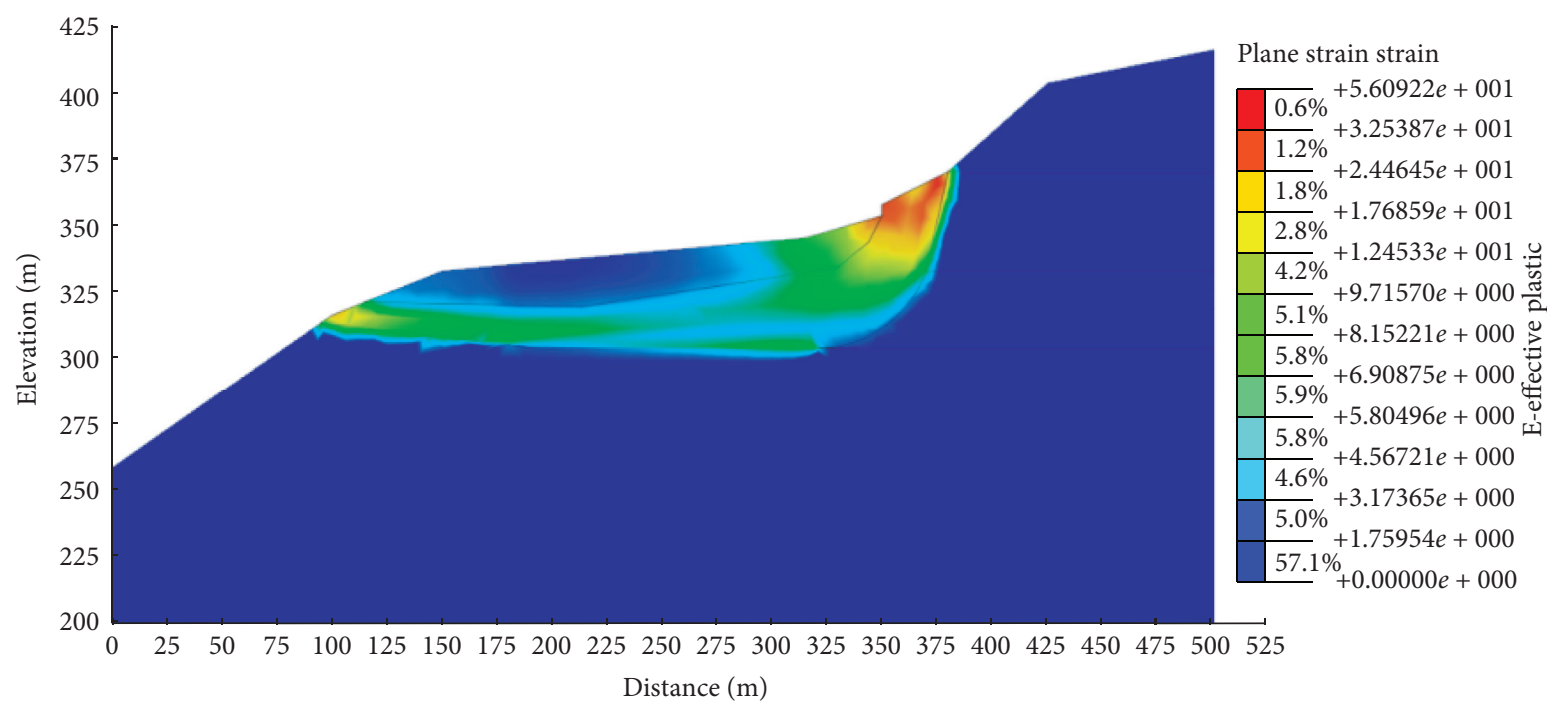

Figure 15: Plastic strain diagram of working condition 5.

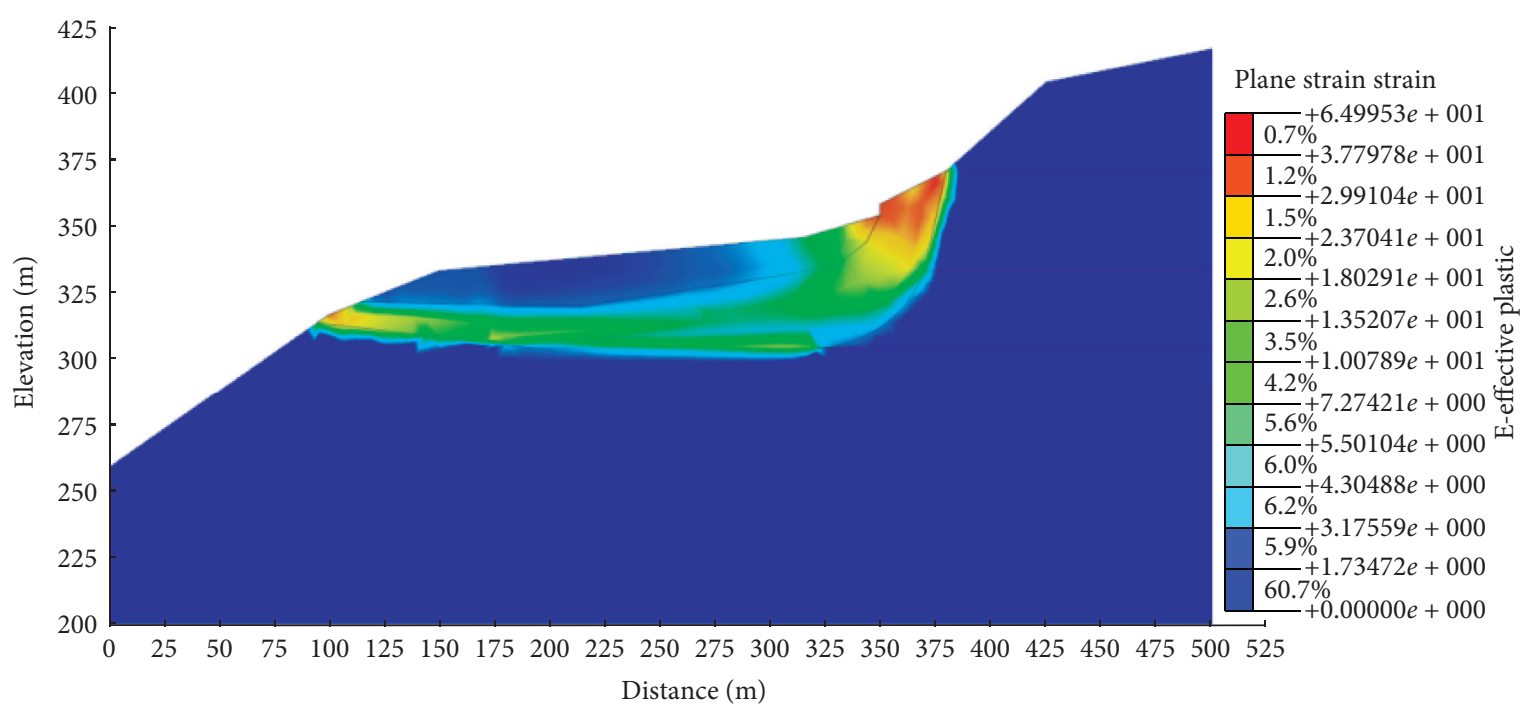

FIgURE 16: Plastic strain diagram of working condition 6. 
TABLE 3: Slope safety coefficient in the six working conditions.

\begin{tabular}{lcccccc}
\hline & Model 1 & Model 2 & Model 3 & Model 4 & Model 5 & Model 6 \\
\hline Stability coefficient & 1.151 & 1.125 & 1.087 & 1.062 & 1.049 & 1.042 \\
\hline
\end{tabular}

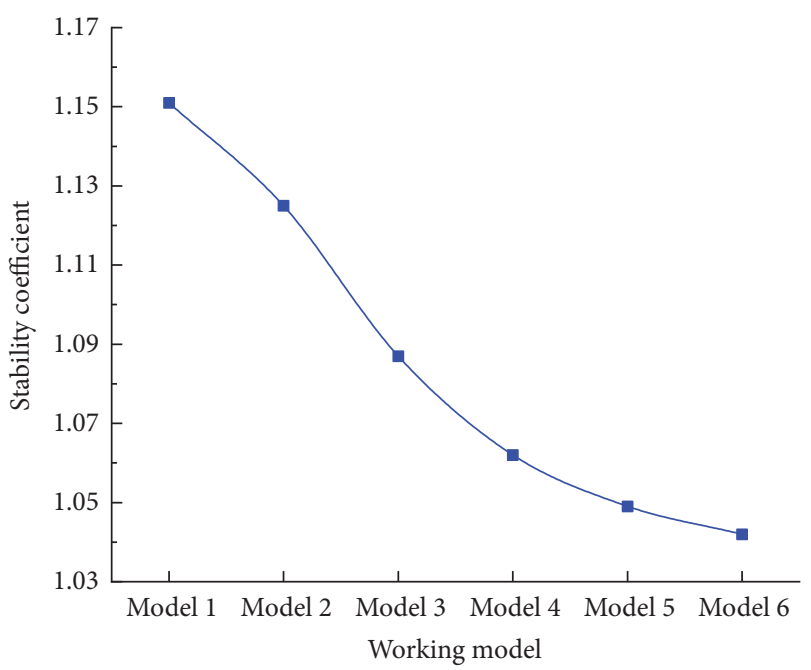

Figure 17: Variation diagram of the landslide stability coefficient with different rainfall intensities.

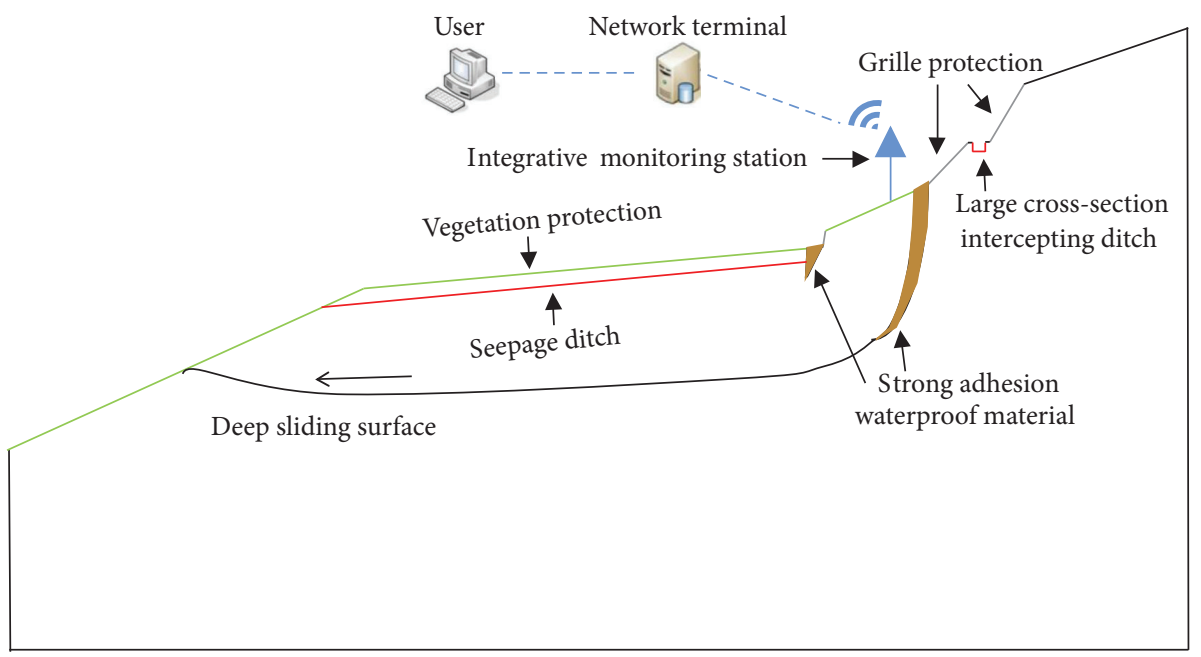

FIGURE 18: Schematic of prevention and treatment measures.

(4) In the future, slope cutting and load reduction measures can be applied to reduce the height of the unstable part of the slope if engineering measures for reinforcement need to be taken after relevant research and demonstration [28-30].

\section{Discussion}

The accurate judgment of landslide stability plays an essential guiding role in slope engineering. This paper uses the qualitative and numerical analysis methods to study the failure mechanism and influencing factors of the Xiashan landslide. By analyzing the monitoring data, we conclude that rainfall has a strong influence on the slope deformation, and the landslide is in a creep state. The numerical simulation results also prove this conclusion.

In a previous study of the Xiashan landslide, $\mathrm{Yu}$ [31] established a Xiashan landslide model with different groundwater levels for stability analysis. Zhu [32] evaluated the stability of the Xiashan landslide on the basis of survey results. Their studies indicated that rainfall is the main factor that causes the Xiashan landslide to slip. After more than 10 years, the latest survey results, monitoring data, and rainfall conditions of the Xiashan landslide have changed. This article selects SRM in Midas GTS NX software for simulation. Its correctness is dependent on the mechanical parameters of the rock and soil measured in the previous test, but it can quickly and accurately simulate the working 
conditions that simultaneously consider rainfall and groundwater. Compared with the results of other studies, the development of cracks changes the failure mechanism of the Xiashan landslide. We conclude that the Xiashan landslide has transformed from the sliding tensile cracking type to the hydraulic driving type. We quantify the impact of rainfall intensity on the landslide stability and find that the critical rainfall intensity of the Xiashan landslide from the relatively stable stage to the unstable stage is $200 \mathrm{~mm} /$ day.

Although this paper has obtained many useful conclusions on the study of the Xiashan landslide, many deficiencies still need to be improved gradually. The monitoring data used for analysis in this paper are only the monitoring data from the first half of 2020 with a small amount of rainfall. The conclusions drawn from monitoring data with shorter time periods appear to be inadequate. Therefore, long-term monitoring data collection and analysis need to be continued. Also, the rainfall intensity in the numerical simulation study is the quantified data, so the difference between the effect of short-term heavy rainfall and long-term continuous rainfall on the landslide needs to be further studied. In addition, the specific mechanisms between rainfall and groundwater and between groundwater and rock must be studied in detail.

\section{Conclusions}

In this study, the geological conditions, present situation, rainfall, monitoring data, and numerical simulation results of the Xiashan landslide are analyzed. The current Xiashan landslide belongs to the failure mode caused by hydraulic drive. The deformation mode of the landslide is creeping deformation. The joints and fissures of rock mass are developed, and the eruption and sedimentary layers always appear alternately, which is unfavorable to the stability of the landslide. The latest monitoring results and numerical simulation prove that rainfall is the main factor that affects the slope stability.

The calculation results show that the stability coefficient is less than 1.05 when the rainfall intensity is more than $200 \mathrm{~mm} /$ day. This finding indicates that the slope is in an unstable state and is prone to sliding rapidly. Considering the influence of typhoons, the probability of heavy rain in the landslide area is extremely high, and a large rainstorm (daily rainfall $>250 \mathrm{~mm}$ ) may occur. Therefore, long-term monitoring and various drainage measures should be applied to implement comprehensive treatment.

\section{Data Availability}

The data used to support the findings of this study are included within the article.

\section{Conflicts of Interest}

The authors declare that they have no conflicts of interest regarding the publication of this paper.

\section{Acknowledgments}

The authors acknowledge the financial support of the funding of the State Key Laboratory of Frozen Soil Engineering (Grant nos. SKLFSE201815 and SKLFSE201712) and the support of the Key Laboratory of Rock Mechanics and Geohazards of Zhejiang Province (Grant no. PCMGH2016-Z-04).

\section{References}

[1] M. Huang, C. Hong, S. Du, and Z. Luo, "Experimental technology for the shear strength of the series-scale rock joint model," Rock Mechanics and Rock Engineering, vol. 53, no. 12, pp. 5677-5695, 2020.

[2] M. Huang, D. Liu, C. Hong et al., "Representative sample sampling method for size effect experiment of jointed rock mass," Geofluids, Article ID 8870387, 2020.

[3] Z. C. Tang, "Experimental investigation on temperature-dependent shear behaviors of granite discontinuity," Rock Mechanics and Rock Engineering, vol. 53, no. 9, pp. 4043-4060, 2020.

[4] Z. C. Tang and Y. Zhang, "Temperature-dependent peak shear-strength criterion for granite fractures," Engineering Geology, vol. 269, Article ID 105552, 2020.

[5] Z. C. Tang, Q. Z. Zhang, J. Peng, and Y. Y. Jiao, "Experimental study on the water-weakening shear behaviors of sandstone joints collected from the middle region of Yunnan province, P.R. China," Engineering Geology, vol. 258, Article ID 105161, 2019.

[6] F. Cai and K. Ugai, "Numerical analysis of rainfall effects on slope stability," International Journal of Geomechanics, vol. 4, no. 2, pp. 69-78, 2004.

[7] S. Wang, W. Xu, J. Liu, and G. Garcea, "Stability and failure mechanism analyses of the Zhenggang landslide in southwestern China," Advances in Civil Engineering, vol. 2018, Article ID 6128401, 2018.

[8] M. L. Chen, P. F. Lv, W. Z. Nie et al., "The role of water and lithology on the deformation and failure of an anaclinal rock slope in a hydropower reservoir," Advances in Civil Engineering, vol. 2020, Article ID 8852227, 2020.

[9] J.-w. Zhou, H.-b. Li, G.-d. Lu, Y. Zhou, J.-y. Zhang, and G. Fan, "Initiation mechanism and quantitative mass movement analysis of the 2019 Shuicheng catastrophic landslide," Quarterly Journal of Engineering Geology and Hydrogeology, vol. 54, no. 2, Article ID qjegh2020, 2020.

[10] R. M. Iverson, "Landslide triggering by rain infiltration," Water Resources Research, vol. 36, no. 7, pp. 1897-1910, 2000.

[11] M. Calvello, L. Cascini, and G. Sorbino, "A numerical procedure for predicting rainfall-induced movements of active landslides along pre-existing slip surfaces," International Journal for Numerical and Analytical Methods in Geomechanics, vol. 32, no. 4, pp. 327-351, 2008.

[12] Y. Zhou, S.-c. Qi, L. Wang, M.-l. Chen, C. Xie, and J.-w. Zhou, "Instability analysis of a quaternary deposition slope after two sudden events of river water fluctuations," European Journal of Environmental and Civil Engineering, vol. 3, pp. 1-19, 2020.

[13] R. M. Iverson, D. L. George, K. Allstadt et al., "Landslide mobility and hazards: implications of the 2014 Oso disaster," Earth and Planetary Science Letters, vol. 412, pp. 197-208, 2015.

[14] E. Conte, L. Pugliese, and A. Troncone, "Post-failure analysis of the Maierato landslide using the material point method," Engineering Geology, vol. 277, Article ID 105788, 2020.

[15] E. L. Harp, M. E. Reid, J. P. Mckenna, and J. A. Michael, "Mapping of hazard from rainfall-triggered landslides in 
developing countries: examples from Honduras and Micronesia," Engineering Geology, vol. 104, no. 3-4, pp. 295-311, 2009.

[16] Y. N. Lu, X. H. Wu, and X. P. Li, "Stability analysis and countermeasures on landslide of mountain expressway," Construction Technology, vol. 43, no. 5, pp. 92-96, 2014, in Chinese.

[17] Y. Miyabuchi, F. Maeno, and S. Nakada, "The October 16, 2013 rainfall-induced landslides and associated lahars at Izu Oshima Volcano, Japan," Journal of Volcanology and Geothermal Research, vol. 302, pp. 242-256, 2015.

[18] Xinchang County Annals Compilation Committee, Xinchang County, Xinchang County Annals, Shanghai Bookstore, Shanghai, China, 1994, in Chinese.

[19] Standardization Administration of China, GB 18306-2015 Seismic Ground Motion Parameters Zonation Map of China, China Standards Press, Beijing, China, 2015, in Chinese.

[20] C. H. Liu, J. Xu, C. L. Cao, C. X. Chen, and X. T. Feng, "Analysis of bedding-slip failure mechanism of rock slope due to hydraulic drive," Chinese Journal of Rock Mechanics and Engineering, vol. 24, no. 19, pp. 3529-3533, 2005.

[21] Q. J. Hu, R. D. Shi, L. N. Zheng, Q. J. Cai, L. Q. Du, and L. P. He, "Progressive failure mechanism of a large bedding slope with a strain-softening interface," Bulletin of Engineering Geology and the Environment, vol. 77, no. 1, pp. 69-85, 2017.

[22] S. L. He, X. J. Guo, F. Y. Li, N. Li, and X. W. He, "Spatiotemporal variation of rainfall and rainfall erosivity in southern China in recent 60 years," Resources \& Environment in the Yangtze Basin, vol. 26, no. 9, pp. 1406-1416, 2017, in Chinese.

[23] K. Emanuel, "Increasing destructiveness of tropical cyclones over the past 30 years," Nature, vol. 436, no. 7051, pp. 686-688, 2005.

[24] D. V. Griffiths and P. A. Lane, "Slope stability analysis by finite elements," Géotechnique, vol. 49, no. 3, pp. 387-403, 1999.

[25] T. Matsui and K.-C. San, "Finite element slope stability analysis by shear strength reduction technique," Soils and Foundations, vol. 32, no. 1, pp. 59-70, 1992.

[26] Y. C. Ma, P. D. Su, and Y. G. Li, "Three-dimensional nonhomogeneous slope failure analysis by the strength reduction method and the local strength reduction method," Arabian Journal of Geosciences, vol. 13, no. 1, p. 21, 2020.

[27] W. Gao, X. Chen, X. Wang, and C. J. Hu, "Novel strength reduction numerical method to analyse the stability of a fractured rock slope from mesoscale failure," Engineering with Computers, pp. 1-17, 2020.

[28] L. Abramson, T. Lee, G. Boyce, and S. Sharma, Slope Stability and Stabilization Methods, John Wiley \& Sons, New York, NY, USA, 2nd edition, 2002.

[29] T. Ito and T. Matsui, "Methods to estimate lateral force acting on stabilizing piles," Soils and Foundations, vol. 15, no. 4, pp. 43-59, 1975.

[30] E. Conte, A. Troncone, and M. Vena, "Behaviour of flexible piles subjected to inclined loads," Computers and Geotechnics, vol. 69, pp. 199-209, 2015.

[31] B. T. Yu, H. Y. Sun, Y. Q. Shang, and H. Q. Li, "Characteristics and stability analysis of Xiashan landslide in Zhejiang province," Chinese Journal of Rock Mechanics and Engineering, vol. 25, no. S1, pp. 2875-2881, 2006.

[32] L. R. Zhu, G. S. Mao, K. D. Li, Z. G. Cheng, and E. K. Mao, "The geological characteristics and stability analysis of the Xiashan village landslide in Xinchang county, Zhejiang province," The Chinese Journal of Geological Hazard and Control, vol. 19, no. 4, pp. 18-22, 2008, in Chinese. 